Short Communication

\title{
Effect of Mixed Bacteria on Corrosion Properties of Zn-Al-Cd Sacrificial Anode
}

\author{
Jiwen Song ${ }^{1}$, Jie Zhang ${ }^{2,4,5^{*}}$, Jia Wang ${ }^{2,3}$, Xiuxia Song' ${ }^{2}$, Shengli Chen ${ }^{1}$ \\ ${ }^{1}$ CNOOC Information Technology Co., Ltd, Shenzhen, 518067, China \\ ${ }^{2}$ Key Laboratory of Marine Environmental Corrosion and Bio-fouling, Institute of Oceanology, \\ Chinese Academy of Sciences, Qingdao, 266071, China. \\ ${ }^{3}$ University of Chinese Academy of Sciences, Beijing, 100049, China. \\ ${ }^{4}$ Open Studio for Marine Corrosion and Protection, Pilot National Laboratory for Marine Science and \\ Technology, Qingdao 266237, China \\ ${ }^{5}$ Center for Ocean Mega-Science, Chinese Academy of Sciences, Qingdao, 266071, China \\ *E-mail: zhangjie@qdio.ac.cn
}

doi: $10.20964 / 2019.02 .30$

Received: 17 August 2018 / Accepted: 30 October 2018 / Published: 5 January 2019

\begin{abstract}
In this paper, the mixed microorganism (sulfate reducing bacteria and Shewanella algae) on corrosion behavior of Zn-Al-Cd sacrificial anode has been studied using electrochemical impedance spectroscopy (EIS), scanning electron microscopy (SEM) and fluorescence microscopy. The EIS results showed that the corrosion rate of mixed bacteria samples has experienced a process of increasing first and then decreasing as the test time is extended. SEM and fluorescence microscopy results showed that bacteria have undergone a process from mass propagation to the formation of a layer of biofilm on the surface of the sample. This layer of biofilm formed by bacteria, corrosion products and bacterial metabolites protects the sample, avoiding contact of corrosive media with the sample, thereby reducing the corrosion rate of the sample.
\end{abstract}

Keywords: Electrochemical impedance spectroscopy; Microbiologically influenced corrosion; Zn-AlCd sacrificial anode; Fluorescence microscopy

\section{FULL TEXT}

(C) 2019 The Authors. Published by ESG (www.electrochemsci.org). This article is an open access article distributed under the terms and conditions of the Creative Commons Attribution license (http://creativecommons.org/licenses/by/4.0/). 